\title{
An emerging model for life sciences commercialization
}

\begin{abstract}
Ashley J Stevens
\end{abstract}
There are challenges in transplanting the US-European technology transfer model to emerging economies.
Since 2000, the institutional ownership model has spread to emerging nations, where governments have encouraged and supported these initiatives in the hopes of seeing some of the economic development benefits that have accrued in the United States and Europe. Yet, through my varied experience-director of the Office of Technology Transfer at Boston University and the DanaFarber Cancer Institute; co-founder of biotech companies Genmap (from which emerged Myriad Genetics) and Kitogenics; president of the Association of University Technology Managers; instructor of technology transfer and early-stage technology commercialization in more than 20 countries-it has become apparent to me that there are several structural issues in transplanting the US-European technology transfer model to emerging economies.

\section{Tech transfer in developed economies}

There are many inherent problems with the business model of technology transfer. Consider the path that awaits a new university wanting to establish a technology transfer program. It needs to understand and accept that there will be upfront costs that might be prohibitive, and a payoff much further down the road than many institutions and governments would be prepared to accept. Once that is accepted, a university then needs to do the following.

- Hire (and pay) technology transfer office (TTO) staff. If the country is new to this endeavor, there likely won't be local experienced staff, and the best possible candidates will need training abroad before being able to slowly learn on the job.

- Once trained, staff will need to educate faculty on what technology transfer is. Most professors will likely not have thought about applying the results of their science to realworld problems.

- When faculty eventually begin identifying real-world applications for their scientific discoveries and submitting invention dis-
Ashley J. Stevens is President of Focus IP Group, Winchester, Massachusetts, USA. e-mail: astevens@bu.edu closures, the new office will need to evaluate these disclosures for patentability and commercial potential. For those chosen, the institution must pay for the resulting patent applications.

- After patenting, TTO staff will need to market the inventions. Because academic science is usually well ahead of industrial research, finding a company for licensing takes time-in the United States, the median time from disclosure to license is four years.

- Even the best technology transfer programs license only $20-25 \%$ of the invention disclosures they receive ${ }^{1}$; the investment the university has made in patenting the other $75 \%$ will be written off. (Typically, universities file at least initial provisional patent applications on $\sim 60 \%$ of the invention disclosures they receive.)

- If successfully licensed, the licensee will need to develop the technology and convert it into commercial products. This also takes time, and the technology may not work in the intended application or may not be costeffective-in the United States, only 3\% of invention disclosures result in marketed products (http://www.autm.net/resourcessurveys/research-reports-databases/stattdatabase-(1)/).

- For successful products, the institution will receive royalties on the sales of the marketed products. Yet, most products are not massive sellers. In the United States and across research disciplines, only 227 licenses (out of 45,000 total active licenses, of which 10,500 licenses were generating running royalties on product sales) generated more than \$1 million in royalties in 2015 (http:// www.autm.net/resources-surveys/researchreports-databases/statt-database-(1)/).

- Of this royalty money, a TTO will typically give away $75 \%$ or more to the inventors and as grants for research, as specified in the institution's intellectual property (IP) policy ${ }^{2}$. 
Table 1 Total research funding ${ }^{\mathrm{a}}$ per invention disclosure in 2011

\begin{tabular}{lc} 
Region & Total research funding per invention disclosure (\$ millions) \\
\hline Chile & 1.1 \\
USA & 2.8 \\
Canada & 3.0 \\
Europe & 3.6
\end{tabular}

ancludes governmental, intergovernmental, foundation and philanthropic, and industrial sources. Sources: Chile: Survey conducted by AUTM for CORFO; US and Canada: AUTM Annual Licensing Surveys 2011; Europe: ASTP Annual Licensing Survey, 2011

- Finally, the patents will expire and royalties will cease, so effort and time needs to be invested to manage the life cycle of the IP by maintaining existing patents and starting the cycle again.

It is, therefore, no surprise that all attempts to make technology transfer a for-profit business have failed. Thus, if a university or country, facing this unattractive business model, retains its desire for a technology transfer ecosystem, it must consider the following points.

Return on investment. It will likely be years before their technology transfer platform will be self-supporting. A study of US TTOs, looking at data for 2006, found that over half of them spent more money than they brought in, and only 16\% kept enough of their income after distributions to inventors and grants for research to cover their costs ${ }^{3}$. It is not uncommon to find newly established TTOs with substantial patent portfolios, all unlicensed. Patenting is relatively easy-hire creative faculty, incentivize them to disclose and pay your patent lawyers, and you will certainly get patents. Licensing them is much tougher.

So, if it's not about the money, what is technology transfer about? The answer is economic development. Technology transfer can rejuvenate existing companies and create new startup companies solving local needs and servicing local industries and companies.

Government support. However, universities hate operations that do not support themselves-consider Harvard president John Kirkland's immortal phrase: "Every tub on its own bottom." This has led to university presidents telling their government that if schools are required to bolster the local economy, the government is going to have to pay for it. The UK government accepted this concept. Just as the government pays universities to teach and to carry out research, it introduced "Third Stream" funding to support economic development via the Higher Education Innovation Fund program in $2002 / 2003$, making $£ 160$ (\$207) million annually available to UK uni- versities to support their TTOs. The most recent assessment of university research programs in the UK awarded $25 \%$ of the score based on the impact of the research.

Long-term vision and patience. That government support will have to last a long time-Denmark and Japan each supported university tech transfer activities for ten years when they changed their legal systems to an institutional ownership model in 1999-2000. France committed $€ 1$ ( $\$ 1.1$ ) billion over ten years to fund regional technology transfer centers via the SATT (Société d'Accélération du Transfert de Technologie) program in 2010. This is not an injection of money for a quick result.

\section{Tech transfer in emerging economies}

There is less evidence of support for technology transfer in countries with emerging economies. Yet, working in these countries, I have discovered a couple of things. The first is that innovation is everywhere. I've encountered university innovations in Chile, Colombia, Portugal-the list goes on-particularly in food and agriculture. These discoveries were every bit as creative and original as those from universities in advanced economies. With the right coaching, supplied by organizations such as Stanford Research Institute in California and the University of Texas Austin's IC2 Institute, these ideas can be turned into compelling investment pitches. The entrepreneurial spirit of students transcends national boundaries, and the current generation of students is the most entrepreneurial ever.

The second thing is that there are amazing managers in incubators, such as the CRECE incubator in Talca, Chile; the Ruta $\mathrm{N}$ incubator in Medellín, Colombia; the Berytech Technological Pole in Lebanon; and the UniVenture incubator in Les Berges du Lac, Tunisia. Incubators are the de facto business schools of entrepreneurship in their countries. The incubator managers coach their companies on business plans and pitches, they know where the (somewhat limited) local sources of investment are, they know which big companies are receptive to acquiring external technology and forming partnerships, and so forth.

That's the good news. Unfortunately, for a sustainable life sciences sector to develop in an emerging economy, a host of challenges can stymie commercialization, despite a wealth of entrepreneurial endeavor and innovative science. Here are some of the challenges.

University level. In emerging economies, universities generally prioritize their undergraduate programs. Class sizes are large and the faculty-to-student ratio is much higher than at universities in developed countries. As a result, professors are teachers first and researchers second, which is just as well, since government funding for science is also much lower than in developed countries.

As part of an engagement with CORFO, the industrial economic development agency of the Chilean government, Chilean universities reported their 2011 data to the Association of University Technology Managers (AUTM) Annual Licensing Survey, which has been carried out in the United States and Canada since 1991. The results showed that if all the academic research in Chile were rolled into a single institution, it would have ranked $103^{\text {rd }}$ in the United States, on par with Tulane University.

And because research funding is so low, graduate programs, particularly doctoral programs, are small or non-existent. Thus, the best and the brightest go to the United States or Europe for graduate studies, from which many do not want to return.

The study did show that the rate of invention per dollar of research in Chile is higher than in the United States (Table 1). Though the rate of invention in Chile has likely increased since 2011, the data don't necessarily prove that Chilean scientists are inherently more inventive than their North American and European counterparts; rather, the difference reflects in large part lower academic salaries in Chile. This pattern is unlikely to be limited to Chile, since academic salaries are generally lower in most emerging economies compared to developed ones.

Brain drain. This was mentioned above as one of the problems for universities. Frequently, the brightest and the best in emerging economies go abroad for training and advanced degrees. Once they have seen the opportunities available, they frequently endeavor to stay in these countries and their talents are lost to their homeland. As a result, governments in developing countries may be reluctant to create opportunities for their young stars to travel abroad for training. 
The Triple Helix. Another key differentiating factor is government policies toward commercialization. In the past 25 years, the so-called Triple Helix model (Box 1) has come to the fore in developed economies. This model relies on academic institutions, industry and government working in a coordinated ecosystem to spur commercialization, relying on closer ties between all three. In contrast, most emerging economy governments do not subscribe to the Triple Helix model of economic development. Similar to the United States before 1993, they expect universities only to supply a skilled workforce, not to be a source of innovation that can drive economic development in the country. And, as discussed earlier, these governments do not fund academic research to any significant extent, and therefore do not see a need to support TTOs to transfer research to companies.

Some of the other issues are:

- In many cases, industrial R\&D is only marginal or non-existent (e.g., limited to generic drugs or service providers), and there are few researchers to interact and share translational knowledge with academics.

- Policy makers generally don't have the longterm vision or commitment to stick to the long investment timelines needed. Even Singapore has been criticized for retreating from its R\&D-intensive model with an obsession over metrics.

- Frequently, policy makers try to force the establishment of 'local' clusters of companies. The Japanese government set a target of 1,000 university spin-out companies in 1999. More than 1,000 were duly reported as having been created, but few of that first cohort survive today, because biotech companies need to be competitive globally in order to succeed. Clusters have to evolve over time.

Companies look abroad. Although they lack the broad industrial bases of developed nations, many countries with emerging economies boast major companies. Every nation has one or more cellular telephone companies, and there are frequently large, domestically owned entities focused on natural resources or agriculture. Fewer have domestic pharmaceutical companies, and those that do tend to produce generics, though South Africa's Aspen Pharmacare (Durban, South Africa) leveraged licenses to AIDS drugs from US and European companies in the early 2000s, transforming itself into a major research-based company.

Still, flagship companies in emerging economies are rarely interested in fostering local economic clusters of companies to support their industry. For example, Aspen's deal mak-

\section{Box 1 The Triple Helix}

In 1993, a cover story in Business Week ${ }^{7}$ identified a new model of economic development in the United States, based on transferring university innovation to industry for development and commercialization, all supported by government. This critical role of universities in economic development was in stark contrast to previous industrial policy initiatives, in which government looked to, and supported, only industry to spur innovation. Reflecting the three constituencies involved, Etzkowitz labeled this new model the "Triple Helix"8.

Perhaps the most dramatic example of the Triple Helix at work is in Massachusetts, where in 1980 the economy was solidly high tech and there were only a few small startup biotech companies that had been spun out of Harvard, Tufts and Boston Universities, and MIT. In 1987, the Massachusetts Biotechnology Research Park opened across the street from the University of Massachusetts Medical School, the first dedicated biotech research park anywhere in the world, which housed a Harvard AIDS spin-out, Cambridge Biotech, as well as an incubator to spawn the next generation of tenant companies.

Thirty-five years later, Massachusetts is the undisputed leader in pharmaceutical research in the world, due to its unparalleled cluster of seven major research universities and, very importantly, 14 affiliated teaching hospitals, and to a creative and tenacious venture capital community ${ }^{9}$. MassBIO, the industry lobby for life sciences in Massachusetts, has grown to more than 975 members. Lawyers, companies, consultants, government and sources of investment capital in the cluster have become comfortable with universities and have developed ways to work with them to translate technologies and spur economic development.

ing appears focused more on global expansion than creating a South African biotech cluster, and it looks to North America and Europe for innovation.

This phenomenon in emerging economies is not unique to the life sciences. The copper mining industry in Chile is one of the largest in the world, yet there is no cluster of Chilean companies supplying equipment, materials, components, services and expertise to support the industry. The mining companies' interactions with Chilean universities are minimaloccasional contracts for material testing, for example-despite there being a number of professors who study copper mining and have identified potential solutions to some of the problems unique to the Chilean industry. Rather, the major Chilean copper companies look to engineering companies in Germany and Switzerland for process improvements and improved equipment.

Another issue is the lack of $\mathrm{R} \& \mathrm{D}$ personnel with translational expertise, people able to go back and forth between companies and academic positions, or to form management teams for small or medium-sized enterprises SMEs and act as receptors for academic innovation. In China, for example, the government is keen to move industry into innovative $\mathrm{R} \& \mathrm{D}$, but many of the companies there lack any significant R\&D resources (Box 2).

Lack of licensing expertise. Commerce in countries with emerging economies is primarily focused on products and contract services rather than technologies, and innovative products are generally developed abroad, not locally, with the technology transferred through multinational companies. As a consequence, there is little expertise in the art of licensing technology in emerging economies. Life sciences is probably the most intricate and sophisticated area of licensing among industries, so it is particularly hard for universities in such countries to begin out-licensing technologies to startup biotech companies.

This lack of licensing expertise is evident looking at the Licensing Executives Society International (LESI; Atlanta), the major organization representing corporate licensing executives worldwide. LESI was founded in the United States in 1965, reflecting the relatively recent emergence of licensing as an important business activity even in the United States.

There are now 33 member societies in LESI, 31 in individual countries or pairs of countries (e.g., the United States and Canada, Benelux, Czech Republic and Slovakia) and two regional associations (Andean Countries and Arab Countries). Only nine of the individual country associations are for emerging nations outside of North America and Europe, and they appear to be relatively inactive in terms of putting on events, training courses and the like.

In the United States, executives from industry, myself included, were recruited by universities to lead their technology transfer offices in the 1980s and 1990s. In developing countries, leading companies generally do not have 


\section{Box 2 China rising}

As is the case in many industries, China bears watching in biotech. It has the most active patent office in the world-SIPO, the State Intellectual Property Office of China, processed more than 1 million patent applications in 2015 (ref. 10). There were also several times more infringement suits filed in China than in the United States (14,202 in China vs. 5,600 in the United States) ${ }^{11}$, though damages are a fraction of what is routinely awarded in the United States, and are usually limited to $\$ 150,000$ per case ${ }^{12}$ China also has a growing base of venture capital, with some Chinese biotechs receiving significant rounds of funding, and large pharma companies are establishing research facilities there. Furthermore, China implemented the institutional-ownership model of technology in October 2015, which specifies that inventors receive $70 \%$ of the income from licensing, so Chinese professors are now highly incentivized to get involved in the process.

China also has the Chinese Academy of Sciences (CAS), with its more than 120 individual research institutes. Lenovo Group, arguably China's first global brand, spun out from the CAS in November 1984. In July 2016, the CAS Intellectual Property Management Center was founded in Beijing to provide a unified platform for the CAS to strengthen the protection and application of intellectual property rights as well as technology transfer. Reportedly, 78 institutes have joined this program. There is also a company called The Chinese Academy of Sciences Holdings, which participates in venture capital and private capital investments as an institutional investor and makes direct investments on companies based on technology from CAS.

people with licensing expertise that universities can recruit, even if the universities understood the need for such people and could justify the salaries it would take to hire them.

Risk capital and undercapitalization of startups. The United States has several well-established pools of risk capital that entrepreneurs can tap into to fund technology development. Beyond the Small Business Innovative Research (SBIR) and related Small Business Technology Transfer (STTR) grants from the US National Institutes of Health, there are legions of philanthropic sources and angel investors to help launch companies. And of course the United States has long provided large amounts of venture capital to its thriving biotech industry. Data from Dow Jones Venture Source show $\$ 5.1$ billion was invested into US biotechs in 2016. This is far greater than in Europe, which saw $\$ 1.3$ billion, or in India, which pulled in just $\$ 29$ million $^{4}$.

In emerging economies most sources of risk capital for translational university research are missing. There are certainly rich individuals, who can serve as angel investors, but in emerging economies they are typically only interested in investing in market-ready projects, and these individuals often lack the expertise to invest in life science startups. Thus, early investment is hard to come by. An incubator in Chile described its companies as raising investment rounds of $\$ 10,000, \$ 20,000$, maybe $\$ 50,000$. Only one company had raised a round of $\$ 100,000$, and perhaps unsurprisingly, that was the only company that had achieved scale and self-sustainability. Compare that with the US biotech sector, where the average amount raised in a series A round for 2016 was nearly $\$ 25$ million 4 .

Even in natural-resource-rich economies, where money is available, the skills needed to manage the risks of investing in technology development are frequently absent. Resourcerich economies have little experience in managing market risk-there is no market risk in oil, gas or mineral projects. There is certainly technical risk, in which the geologists were wrong and the expected resource isn't found, and there is the engineering risk of cost overruns. But markets for the products exist, and the only risk is centered on price. As a result, technology investment pools in such countries are frequently mismanaged.

Lack of legal structures. Startup companies need a sophisticated legal ecosystem. They have complex capital structures and require provisions to handle the risk of failure, as bankruptcy is a reasonable possibility. Exits are likely to be by acquisition rather than through offerings on public stock markets, none of which in emerging economies are receptive to loss-making, high-tech companies.

Emerging economies frequently have a less developed and less sophisticated legal infrastructure, which creates bureaucratic barriers to company formation. In Saudi Arabia, for example, a company can have only a single class of stock, so the typical common/series A, $B, C$ preferred stock structure favored by venture capitalists cannot be used.
IP regimes in many emerging economies are less robust than in developed economies, but companies can manage this by using international IP systems, such as the Patent Cooperation Treaty system, to obtain IP protection in major markets.

\section{Solutions}

After the above litany of problems and issues, we have to ask, what are the solutions? I have seen approaches that seem to be working. Few are free, but some are relatively low cost.

Actively network. Expatriates are a valuable resource. Even those that do not return to their homeland generally harbor goodwill toward it and will be prepared to help in whatever way they can. Such help might take the form of mentoring, which can be done over Skype, networking and offering internships. Australia is known for maintaining an active network with its expats, and in the United Kingdom, there is British expatriate in Life Sciences (BELS) that does the same.

Chinese scientists who have spent time in the United States are bringing their new entrepreneurial skills back home. This can have a big impact. A study ${ }^{5}$ of Taiwan's Hsinchu Science Park, the largest in the country and the anchor of the Taiwanese electronics industry, found that by 1996 the park was home to 203 companies employing 54,806 workers. Only 2,563 (4.6\%) were returning expats, but that small percentage had founded $40 \%$ of the companies located there.

Indian life scientists in the United States have started companies and involved scientists back in India. For instance, Mallik Sundaram, Pradip Majumder and Shiladitya Sengupta were scientists working in Cambridge, Massachusetts, and were cofounders of Momenta, Cerulean Pharma and Mitra Life Sciences, among others, before returning to India and founding Mitra Biotech (Naryana Health City, India), Vyome Biosciences (Delhi, India) and Invictus Oncology (Delhi, India) ${ }^{6}$.

Fellowships. Individual TTOs in the United States frequently allow an individual from an emerging economy to work in their office for two to three months to gain experience. When I ran the Office of Technology Development at Boston University, I had more than a dozen fellows come for stays of up to 3 months over the years. Boston University did not charge for this, but the parent institution had to pay the fellow's airfare and living expenses. Fellows needed J-1 visas, which we obtained through Boston University's International Students and Scholars Office (which usually 
took around 3 months), and often we secured accommodation for the fellow in a visiting scholar apartment. This kept a three-month visit to around $\$ 10,000$ - cheap, for the experience gained.

Boston University was also part of the State Department's Humphrey Fellowship program under which mid-career professionals from emerging economies can study at a US university for a year, and some of awardees wanted to study IP and economic development. The State Department would channel them to BU and I'd advise them.

AUTM (AUTM; Oakbrook Terrace, IL, USA) itself has a limited number of emerging country scholarships, allowing those new to the profession to attend AUTM courses and events.

Joint projects. The United States Agency for International Development (Washington, DC) and the European Union (Brussels) fund research partnerships between organizations in advanced and developing countries. Those that have a commercial theme frequently provide funding for a technology transfer component, and this can be an opportunity for substantive interaction and education. Obviously, such an activity has no cost and is actually revenue positive to the emerging economy institution.

Strategic partnerships. The Massachusetts Institute of Technology (MIT; Cambridge, MA, USA) formed several strategic collaborations with countries and universities in emerging economies. The first, in the mid-1990s, was with the UK's Cambridge Universitynot exactly an emerging economy, but one that wanted to emulate the Massachusetts cluster experience and thereby acquire MIT's "technology for technology transfer." Later MIT formed partnerships with King Fahd University of Petroleum and Minerals, in Dammam, Saudi Arabia, and with Russia to help launch the Skolkovo Institute of Science and Technology (Skoltech) in Moscow. Technology transfer was a major component of all those partnerships, and the Cambridge University partnership was very active in life sciences.

Over a three-year period the partnership between AUTM and CORFO in Chile organized training courses and then assigned seven highly experienced consultants to work with 21 Chilean universities and national laboratories to develop five-year strategic plans and one-year operating plans to implement TTOs. However, such programs typically cost many millions of dollars and need to be organized and paid for at the governmental level.
Intergovernmental organizations. The World Bank (Washington, DC) organizes training courses and partnerships to facilitate development of technology transfer in emerging economies, including a World Bank program underway nationwide in Serbia, staffed by two experienced US technology transfer experts. Also, the World Intellectual Property Organization (Geneva) is funding in-depth training programs in half-a-dozen developing countries.

AUTM has partnered with the Asia Pacific Economic Cooperation (Singapore) to offer a series of technology transfer training courses over a three-year period in Asia. A key component has been to identify and train individuals in Asian countries who can absorb the content, adapt it to local circumstances and continue training at the local level, in the local language (though it is critically important that technology transfer professionals be fluent in English, the international language of business).

These programs will typically not charge the emerging economy, though they may need to cover travel expenses for their attendees.

Seeding Labs. Seeding Labs (Cambridge, MA, USA) is a non-profit that seeks donations of obsolete items of life sciences laboratory equipment from Massachusetts universities and companies to refurbish and donate to universities in Africa. These items may be obsolete in Massachusetts, but they are typically vastly superior to the offerings in the African country and allow the recipient universities to compete for international grants and collaborations with life scientists in advanced economies.

Seeding Labs also offers summer fellowships to bring scientists from these countries to Massachusetts to learn such skills as grant writing and project management, and there are opportunities to orient the fellows in technology transfer during these visits.

Forming local tech transfer associations. Several emerging economies have formed associations of their TTOs-SARIMA in South Africa, FORTEC in Brazil and USIMP in Turkey. These groups can now lobby the government for support and funding, and can form international partnerships. Such organizations organize local training courses to educate new recruits for the profession. SARIMA and USIMP have joined the Alliance for Technology Transfer Professionals and help their members become Registered Technology Transfer Professionals (RTTP), an internationally recognized technology transfer credential.
International training. Perhaps the cheapest way to develop technology transfer capability is to hire one of the many retired US technology transfer professionals to teach courses in an emerging economy. A week's course will likely cost less than $\$ 10,000$ for expenses and fees, and will, in addition, establish mentoring relationships that will have continuing value.

\section{Conclusions}

In short, new models will be needed to stimulate the development of biotech ecosystems in emerging economies, and a few have surfaced. One example, which appears robust and sustainable, is the philanthropically funded public-private partnerships (PPPs) that were set up 15 or so years ago and funded by organizations such as the Bill and Melinda Gates Foundation to develop treatments for neglected tropical diseases. PPPs are essentially virtual, developmentonly drug companies that take drugs and vaccines that have already been identified by others in academia and the private sector, and develop them into formulations suitable for delivery in resource-limited environments. The funding to develop the drugs comes from philanthropic and development sources, not from existing drug profits. This allows the drugs to be manufactured by generic manufacturers and sold on a cost-plus basis.

Other models that are likely to be successful in the earlier stages are generic drug manufacturing and contract research organizations to assist with clinical trials in local populations.

All this indicates that emerging economies are unlikely to generate significant drug-focused biotech hubs-at least along the traditional US-European lines-in the near future. It might be more likely that agriculture is an area of innovation, similar to what is happening in Nairobi, Kenya, which is developing a sophisticated hightech agricultural ecosystem, air-shipping produce to Europe and beyond.

Regardless, many technologies start in academic and government research laboratories all over the world, and these institutions must have robust technology transfer infrastructures in place to ensure that scientific data are converted into IP that can be transferred to companies for development, resulting in the creation of high-tech clusters and economic development. The preceding analysis shows that there are severe challenges to creating the technology transfer capabilities needed to harness creative science in many emerging 
economies, and that Triple Helix-style economic development will be slow to emerge in many of them.

\section{COMPETING FINANCIAL INTERESTS}

The author declares competing financial interests: details are available in the online version of the paper.

1. Stevens, A.J. \& Kato, K. LES Nouv. XLVIII, 44-51 (2013).

2. Boston University's Patent Policy, http://www.bu.edu/ policies/employment/patent-policy/.

3. Abrams, I., Leung, G. \& Stevens, A. Res. Manag. Rev. 17.1 (2009).

ன் 4. Lawrence, S. Nat. Biotechnol. 35, 413-420 (2017).

\ 5. Conceiçao, P., Gibson, D.V., Heitos, M.V. \& Shariq, S. (eds.). Science, Technology, and Innovation Policy: Opportunities, and Challenges for the Innovation Economy (Quorum Books, Westport, CT; 2000).

6. Rishi, S. ClO http://www.cio.in/case-study/mitra-biotech-prescribes-perfect-cancer-drug-using-data-analytics (15 April 2014; accessed 22 April 2017.

7. Kelly, K. Hot spots - America's new growth regions, Business Week (19 October 1993).
8. Etzkowitz, H. Triple Helix: a North American Innovation Environment, Technology Access Report, 1993.

9. The Biopharmaceutical Industry in Massachusetts - The Triple Helix in Action, Ashley Stevens, Guest Editorial in The Journal of Biolaw and Business, 10th Anniversary Series, 33-40, May 2007.

10. SIPO. http://english.sipo gov.cn/news/official/201601/ t20160120_1231391.html (State Intellectual Property Office of China, 20 January 2016; accessed
9 May 2017).

11. Schindler, J. IAM http://www.iam-media.com/ blog/detail.aspx?g=d674142d-c88c-4752-af25e6ddc06e2104 (19 February 2016; accessed 9 May 2017).

12. Booth, P. \& Zhang, Y. Law360 https://www.law360. com/articles/885074/chinese-ip-courts-are-increasing-damages-awards (2 February 2017; accessed 9 May 2017).

\section{PODCAST}

\section{First rounders: Jan Vilcek}

Jan is the co-founder, CEO and chairman of the Vilcek Foundation, and also a long-time researcher and professor at New York University's School of Medicine. His conversation with Nature Biotechnology covers his harrowing childhood in Czechoslovakia during the rise of Nazi Germany and World War II, his escape from communist Czechoslovakia through defection, and his role in the discovery of the blockbuster drug Remicade. http://www. nature. $\mathrm{com} / \mathrm{nbt} /$ podcast/index.html

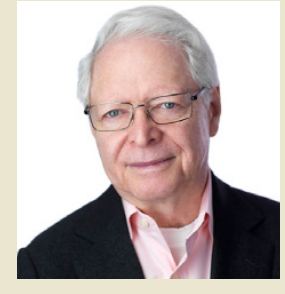


Competing Financial Interests

A.J.S. is president of Focus IP group.

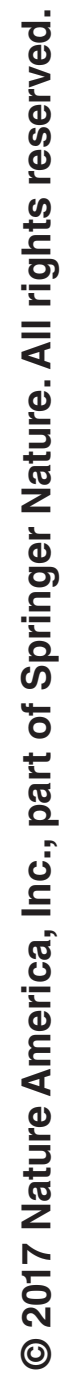

